\title{
IDENTIFICAÇÃO DE ÁREAS DE SUSCETIBILIDADE À INUNDAÇÃO NO SISTEMA HIDROGRÁFICO DO RIO TAVARES EM FLORIANÓPOLIS-SC
}

Marlon de Oliveira Martins ${ }^{1}$ Rodrigo Pinheiro Ribas ${ }^{2}$

Resumo: As ocorrências de inundações em áreas urbanas ocasionam diversos prejuízos, são impactos negativos, que atingem principalmente a população residente em áreas próximas aos leitos dos rios e zonas costeiras. O presente estudo busca validar as cotas de inundação obtidas pelo modelo hidrológico Height Above Nearest Drainage (HAND) a partir de levantamento de campo, indicando assim áreas de suscetibilidade à inundação. A área de estudo é um sistema hidrográfico localizado na porção sudoeste da llha de Santa Catarina, no município de Florianópolis, estado de Santa Catarina. Os eventos de inundação analisados ocorreram entre os dias 9 e 11 de janeiro do ano de 2018 e entre os dias 3 e 7 de julho de 2019, sendo estes selecionados para a análise devido a expressividade do fenômeno em ambas as ocorrências e, também, pela diferença de atuação dos processos fluviais e marinhos. Visto que o primeiro evento se caracterizou por uma inundação ocasionada sobretudo por uma sequência de dias de precipitação de alta intensidade e, o segundo, por ondas de maré de elevada amplitude, visto ser a área de estudo litorânea. Os resultados se mostraram satisfatórios, visto que no teste da qualidade geométrica do Modelo Digital de Terreno (MDT), o PEC-PCD foi enquadrado como Classe A. Os índices de qualidade utilizados para validação da cota altimétrica gerada pelo modelo HAND tiveram estreita relação com os valores obtidos na validação em campo.

Palavras-chave: Inundação. Modelo Digital de Terreno. Geoprocessamento. Modelo HAND. Suscetibilidade à Inundação.

\section{IDENTIFICATION OF FLOOD SUSCEPTIBLE AREAS IN THE HYDROGRAPHIC SYSTEM OF RIO TAVARES IN FLORIANÓPOLIS - SC}

Abstract: Flooding events in urban areas cause several losses and represent negative impacts, which mainly affect the population living close to the riverbeds and coastal areas. This research seeks to validate the flood levels obtained by the Height Above Nearest Drainage (HAND) based on field survey in order to validate the proposed method for the studied area, thus indicating areas of flood susceptibility. The study area consists in a hydrographic system located in the southwestern part of the Santa Catarina Island, in the municipality of Florianópolis, state of Santa Catarina. The flood events analysed took place between January 9th and 11th of 2018 and between July 3rd and 7th, 2019 and were selected for analysis due to the expressiveness in both events and, also, due the differences among fluvial and

\footnotetext{
1 Universidade do Estado de Santa Catarina. Centro de Ciências Humanas e da Educação, Florianópolis, Brasil. marlonmartins.mom@gmail.com, https://orcid.org/0000-0002-5478-3624 2 Universidade do Estado de Santa Catarina. Centro de Ciências Humanas e da Educação, Florianópolis, Brasil.

rodrigo.ribas@udesc.br, https://orcid.org/0000-0002-0054-3123
} 
marine processes. Flooding event in 2018 was characterized by a flood caused due a sequence of heavy rain days and in 2019 by high tide, considering that the study area is coastal. The results were satisfactory to the used digital terrain model geometric quality and was classified as "class A" according to the cartographic exactness patters". The quality indexes used to validate flooding areas from HAND model showed a close relationship with the values obtained in the field validation.

Keywords: Flooding. Digital Terrain Model. Geoprocessing. HAND Model. Flood Susceptibility.

\section{IDENTIFICACIÓN DE ÁREAS DE SUSCEPTIBILIDAD A INUNDACIÓN EN EL SISTEMA HIDROGRÁFICO DEL RÍO TAVARES EN FLORIANÓPOLIS - SC}

Resumen: La ocurrencia de inundaciones en áreas urbanas ocasiona diversos prejuicios. Son impactos negativos que alcanzan principalmente a la población residente en áreas próximas a los lechos de los ríos y en zonas costeras. El presente estudio busca validar las cotas de inundación obtenidas con el modelo hidrológico Height Above Nearest Drainage (HAND) a partir de levantamiento de campo, indicando así áreas de susceptibilidad a inundación. El área de estudio es un sistema hidrográfico localizado en la porción suroeste de la Isla de Santa Catarina, en el municipio de Florianópolis, estado de Santa Catarina. Los eventos de inundación analizados ocurrieron entre los días 9 y 11 de enero del año 2018 y entre los días 3 y 7 de julio del 2019, los cuales fueron seleccionados para el análisis debido a la expresividad del fenómeno en ambas ocurrencias y, también, por la diferencia de actuación de los procesos fluviales y marinos. El primer evento se caracterizó por una inundación ocasionada, principalmente, por una secuencia de días de precipitación de alta intensidad; y el segundo, por olas de marea de elevada amplitud, dado que es un área de estudio localizada en el litoral. Los resultados fueron satisfactorios, dado que en la prueba de calidad geométrica del Modelo Digital de Terreno (MDT) el PEC-PCD fue clasificado como Clase A. Los índices de calidad utilizados para la validación de la cota altimétrica generada por el modelo HAND tuvieron estrecha relación con los valores obtenidos en la validación de campo.

Palabras clave: Inundación. Modelo Digital de Terreno. Geoprocesamiento. Modelo HAND. Susceptibilidad a Inundación.

\section{Introdução}

A ocorrência de desastres ambientais tem se tornado parte do cotidiano de diversas famílias, principalmente nos grandes centros urbanos e áreas mais densamente povoadas. Tais fenômenos podem se caracterizar como sendo de origem natural, estar associado à ação antrópica ou até mesmo de uma junção destes dois aspectos. Segundo Tominaga et al. (2009) os principais processos e fenômenos relacionados à desastres são derivados da dinâmica externa da Terra, 
tais como escorregamentos de solos e/ou rochas, tempestades, enchentes, inundações, dentre outros.

De acordo com Ministério das Cidades (BRASIL, 2007) se caracteriza como enchente ou cheia, a elevação temporária do nível d'água em um canal de drenagem devido ao aumento da vazão ou descarga. Em contrapartida, a inundação é um processo de extravasamento das águas do canal de drenagem para áreas marginais (planície de inundação, várzea ou leito maior do rio), isto quando a enchente atinge uma cota acima do nível máximo da calha do rio. De modo distinto dos alagamentos, estes que ocorrem por inexistência ou insuficiência dos sistemas de drenagem, as inundações têm o fator geomorfológico como determinante. Entretanto, muitas vezes, etapas do planejamento urbano, tais quais a compactação do solo, asfaltamento, retirada de cobertura vegetal, também se convertem em gatilhos e podem assim desencadear inundações, principalmente em áreas próximas à cursos d’água.

A realidade imposta em muitos dos episódios de inundações são as perdas em infraestrutura urbana, eliminação de lavouras, a destruição do patrimônio dos atingidos, a propagação de doenças e, em muitos casos, a perda da própria vida. Cada vez mais se torna importante conhecer as engrenagens dos processos de inundação, e, neste sentido, a modelagem, delimitação e mapeamento de tais fenômenos é etapa fundamental na investigação.

O modelo Height Above Nearest Drainage (HAND) é um modelo hidrológico que representa um terreno suscetível à inundação de acordo com a distância vertical e horizontal do canal de drenagem mais próximo. De forma geral, o modelo normaliza a altitude de uma bacia baseando-se na altura relativa ao longo da rede de drenagem, determinando assim o potencial gravitacional ou relativo da drenagem de uma área. O HAND é, portanto, um Modelo Digital de Terreno (MDT) com altimetria normalizada em relação à rede de drenagem mais próxima. Uma descrição detalhada sobre o modelo HAND, foi apresentada em Renno et al. (2008) e Nobre et al. (2011), estes que introduziram o modelo, bem como as suas bases físicas e hidrológicas.

No modelo HAND, a partir de um MDT, o valor de um pixel é dado pela diferença altimétrica entre seu valor de elevação e a elevação de um pixel pertencente à rede de drenagem mais próxima. Desse modo, quão mais próxima é uma área representada por um pixel do nível de elevação de outro pixel que representa um canal de drenagem mais próximo, mais suscetível é à inundação. 0 
HAND também representa o potencial de drenagem local, que se correlaciona fortemente com a profundidade do lençol freático, uma vez que também considera a distância de um pixel no plano horizontal (RAHMATI et al., 2018). O HAND é, portanto, um índice que apresenta a realidade geométrica da superfície com altimetria normalizada em relação à rede de drenagem mais próxima (RENNO et al., 2008, NOBRE et al., 2011, MOMO et al., 2016, MILANESI, et al., 2017).

Devido à lógica de processamento do modelo HAND, em que se determina as condições hidrológicas do terreno e, consequentemente, áreas de maior potencial de drenagem são destacadas, é possível estabelecer uma relação espacial e/ou temporal acerca da distribuição de áreas com solos úmidos (NOBRE et al., 2016). Ademais, o modelo HAND tem sido amplamente utilizado em diversos estudos, tais quais, análises hidrogeomorfológicas, em avaliação da suscetibilidade a inundações e movimentos de massa, em mapeamento de solos e recursos hídricos, estudos de ecologia vegetal e ribeirinha, entre outros (RAHMATI et al., 2018).

As curvas de nível que podem ser extraídas pelo modelo HAND foram abordadas por Nobre et al. (2015) como "HAND contour", apresentando um novo conceito de curvas de nível normalizada de acordo à distância vertical em relação a uma rede de definida. Desse modo, é possível utilizar a premissa da obtenção de valores altimétricos de referência por critérios analíticos para o HAND contour a fim de delimitar uma superfície potencial de inundação em uma determinada área valendo-se apenas de parâmetros topográficos.

Nesse sentido, Speckhann (2018) analisou a superfície potencial de inundação a partir de seis diferentes descritores de terreno, tendo o índice HAND obtido o melhor resultado de acurácia (91\%). Momo et al. (2016) compararam a acurácia obtida no mapeamento de áreas suscetíveis a inundação com HAND a de modelos de inundação consagrados na literatura internacional, tal qual HEC-RAS 1D, LISFLOOD-FP 1D e TELEMAC 2D. Os resultados mostraram que a acurácia obtida pelo índice HAND em diferentes cotas de inundação é equiparável à dos modelos citados, apesar de que estes dependem do esforço de muitos dados físicos de parâmetro e alta capacidade computacional para processar os modelos matemáticos adotados. O HAND, no entanto, tem seu desempenho mais condicionado à resolução espacial e à qualidade geométrica do modelo digital de elevação ou de terreno de origem.

Observando esse contexto, o objetivo deste estudo é o entendimento da dimensão espacial de incidência dos eventos de inundações na área estudada, que 
corresponde a uma das localidades mais afetadas do município e da região de Florianópolis pelo fenômeno. A estimativa da superfície inundada foi realizada por meio de validação de uma cota altimétrica de inundação de referência utilizando o modelo HAND de Nobre et al. (2011) e, a partir da avaliação dos resultados obtidos por meio de verificação em campo, procedeu-se à determinação de uma superfície de inundação estimada a fim de identificar as áreas de suscetibilidade a inundação.

\section{Área de estudo}

A área de estudo (Figura 1) situa-se na llha de Santa Catarina, porção insular do município de Florianópolis - SC, perfazendo uma área de 57,73 $\mathrm{Km}^{2}$. A delimitação da área foi realizada levando em consideração a dificuldade de realizar uma delimitação precisa na superfície entre bacias, isto devido a área apresentar terrenos arenosos baixos de deposição marinha e estarem contidas num mesmo aquífero. Desse modo, foram observados alguns critérios geomorfológicos para se realizar a delimitação da área de estudo. Inicialmente, foram delimitadas todas as sub-bacias cuja descarga hídrica converge para o curso d’água do rio Tavares.

Num segundo momento, foram delimitadas áreas adjacentes que demonstram possuir uma conexão hídrica superficial ou subsuperficial. Desta forma, a área delimitada consiste num recorte espacial mais abrangente que a própria Bacia Hidrográfica do Rio Tavares, que para este estudo adotou-se um termo que sobressaísse ao de bacia hidrográfica em termos de abrangência espacial e dos recursos hídricos, o de sistema hidrográfico, em que o Rio Tavares é o principal rio da área estudada em termos de comprimento, vazão e área drenada, exercendo a maior influência na dinâmica fluvial. 
Figura 1- Localização geográfica da área estudada.

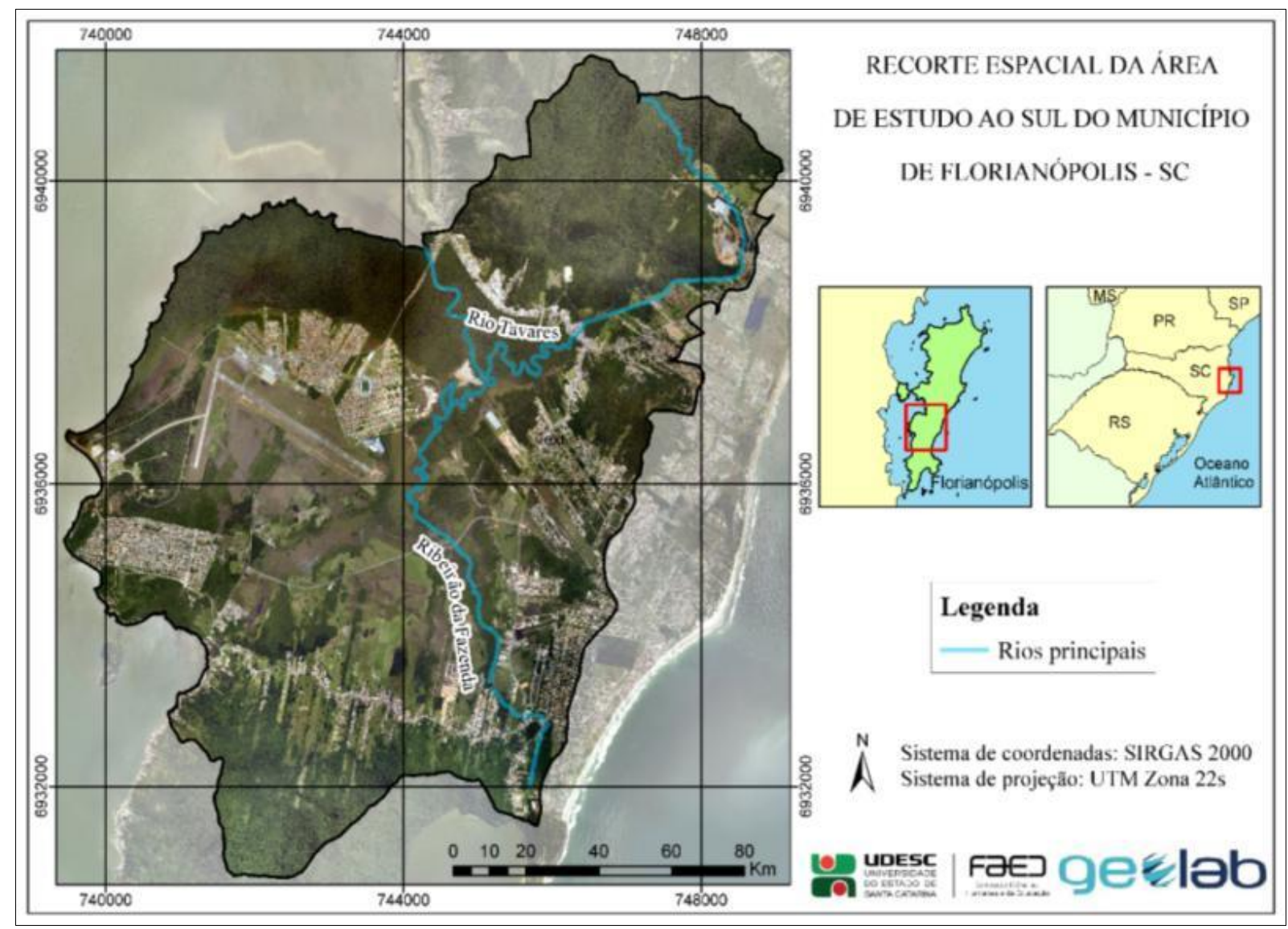

Fonte: Elaboração dos autores

A maior parte dos terrenos que compreendem a área de estudo constitui-se por terrenos da Planície Costeira e cerca de $2 / 3$ da área se encontra a menos de 5 $\mathrm{m}$ do nível do mar. Predominam os terrenos formados a partir de depósitos sedimentares quaternários em planícies lagunares, planícies de maré, terraços marinhos e cordões de restinga, com formações vegetais de Floresta Ombrófila Densa e Manguezais, sendo estes o Manguezal do Rio Tavares e o Manguezal da Tapera (BASTOS, 2004). Contudo, nas periferias da área de estudo nos sentidos Sul e Nordeste, apresentam-se elevações cristalinas, com modelados de dissecação em montanhas, morrarias e colinas, limitando-se à Sul pelo Morro do Ribeirão, o ponto mais alto da Ilha, com 532 metros.

Os rios que integram a área de estudo são de pequeno porte e seus principais tributários têm suas nascentes nas elevações rochosas. O Rio Tavares, o rio principal da área de estudo e que recebe a maior parte da descarga hídrica da bacia, inicia seu curso entre os morros do Sertão e Badejo, situados à Leste, próximo à costa oceânica da Ilha de Santa Catarina, e seu médio e baixo curso tende à Leste, onde recebe seus principais tributários. O maior deles é o Ribeirão da 
Fazenda, que inicia à Sul e corta a maior parte da planície central da área estudada. O Rio Tavares em seu baixo curso atravessa o Manguezal do Rio Tavares e deságua na Baía Sul, na costa leste da llha.

Devido à área de estudo possuir boa parte dos terrenos com altitudes próximas do nível do mar e limites costeiros, eventos de inundação são recorrentes, tornando esse recorte espacial umas das áreas mais suscetíveis à inundação na Grande Florianópolis. Eventos de inundações ocorrem periodicamente e foi uma das áreas fortemente afetadas nos principais registros de inundação da região. Nas diferentes localidades da área, as inundações são causadas por processos fluviais e/ou marinhos. Os eventos de inundação associados a esses processos atuam de maneira associada ou não. Quando associados, se somam ou se anulam, a depender também da localidade da bacia em que o fenômeno é incidente (SANTOS, 2016).

Os eventos mais recentes de inundação de grande expressão ocorreram em janeiro de 2018 e julho de 2019. Entre os dias 9 e 11 de janeiro de 2018 choveu um acumulado de 329,6 milímetros de acordo com os dados meteorológicos concedidos pela Empresa de Pesquisa Agropecuária e Extensão Rural de Santa Catarina (EPAGRI/CIRAM) para esta pesquisa na estação meteorológica da instituição mais próxima da área de estudo. Esse volume representa aproximadamente 131,5\% da média histórica de precipitação para o município no mês de janeiro em apenas 3 dias, de acordo com a base de dados de série histórica do INMET (2010). Consequentemente, nos dias 10, 11 e 12 daquele mês ocorreram inundações nos períodos de atuação de maré positiva, sendo no dia 11 o episódio de maior magnitude, em que vários moradores perderam tiveram que deixar suas casas.

Diferentemente do evento de janeiro de 2018 (Figura 2), causado por associação de chuvas intensas e maré positiva, o evento de julho de 2019 ocorreu pela soma de forçantes de maré astronômica e meteorológica, provocando uma elevação excepcional do nível do mar, sem influência de volume de chuvas. A super maré ou "king tide" - termo utilizado na literatura internacional - ocorrida neste evento foi resultado da combinação de lua em fase nova, eclipse lunar e um centro de baixa pressão criado por um ciclone extratropical. A super maré provocou inundações em vários pontos do município e no Sul do Brasil entre os dias 3 e 7 de julho, sendo que no dia 4 a elevação do nível do mar foi de $163 \mathrm{~cm}$ em Florianópolis (EPAGRI/CIRAM, 2019). Consequentemente, muitos locais de Florianópolis tiveram 
as vias bloqueadas pela água, muitas horas de congestionamentos intensos e desvio do trânsito para outros percursos.

Figura 2- Inundação de 11 de janeiro de 2018, no curso inferior do Rio Tavares.

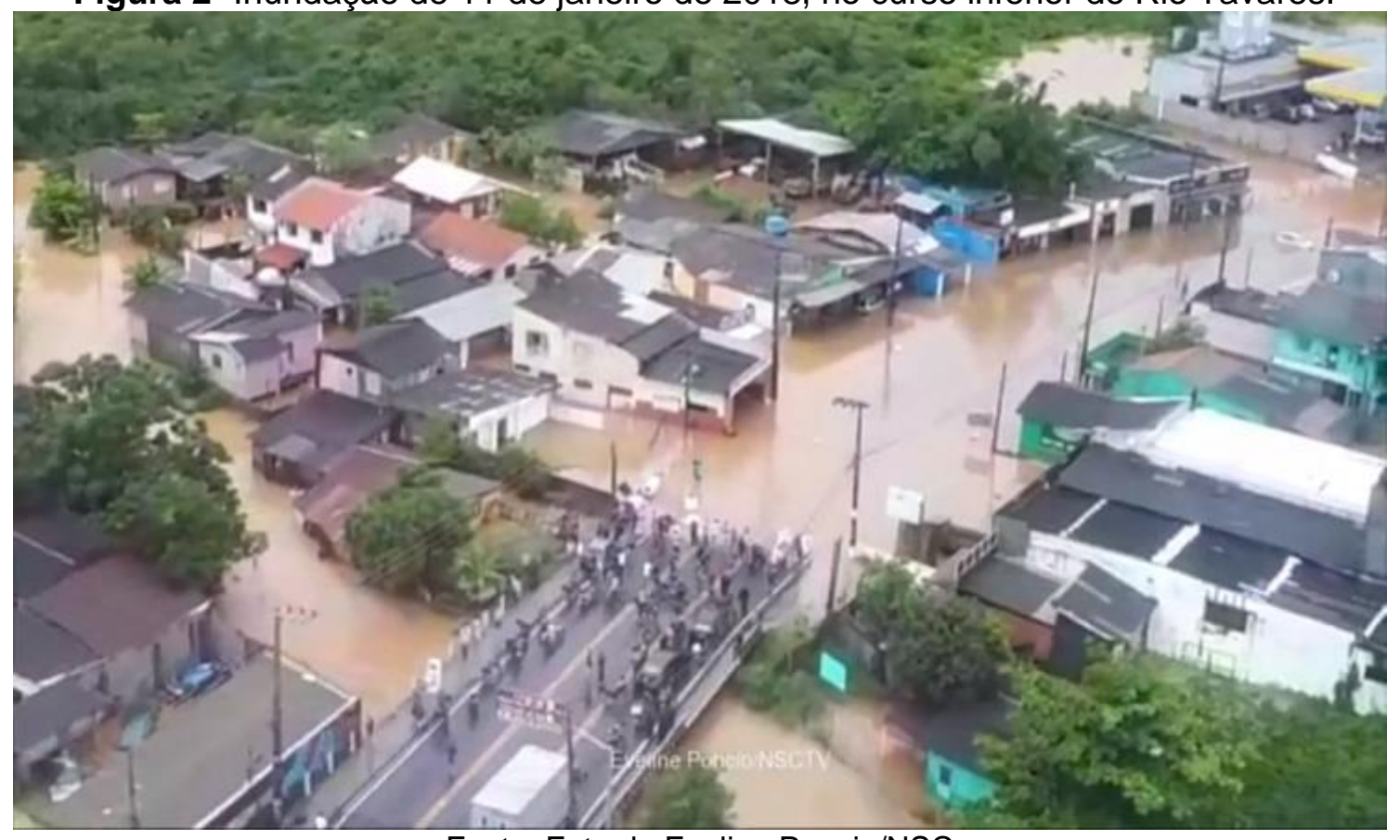

Fonte: Foto de Eveline Poncio/NSC.

\section{Modelagem da área de abrangência de inundação}

$\mathrm{O}$ arquivo do modelo HAND utilizado na pesquisa referente à área de estudo foi criado através do algoritmo desenvolvido por Dilts (2015) no toolbox Topography Tools for ArcGIS 10.3 disponível para o software ArcGIS, este que foi utilizado em todas as etapas de processamento. Para a geração do modelo HAND no algoritmo de Dilts, é necessário um modelo digital de elevação ou de terreno da área em questão e um arquivo matricial dos cursos d'água da mesma área.

Foi utilizado um MDT obtido a partir do levantamento aerofotogramétrico realizado pela Secretaria do Desenvolvimento Econômico Sustentável de Santa Catarina (SDS) entre os anos de 2010 e 2013, este que abrange todo o território estadual, com resolução espacial de $1 \mathrm{~m}$. Para gerar o arquivo matricial dos cursos d'água, foi utilizado um arquivo vetorial dos cursos d'água da Agência Nacional das Águas (ANA). A geração do modelo HAND sucedeu algumas etapas de préprocessamento, que se constituiu na criação de um mosaico do conjunto de arquivos de imagens em formato GeoTIFF do MDT da SDS que abrangem a área de estudo Como a lógica de processamento do modelo HAND não pressupõe áreas sob influência marinha e de corpos d'água costeiro, foi necessário fazer uma adaptação 
considerando toda a linha de costa como sendo um curso d'água, ou seja, a rede de drenagem final.

No procedimento de obter os valores altimétricos do índice HAND, a primeira etapa para normalização dos valores altimétricos diz respeito à correção hidrológica do modelo digital de elevação ou de terreno utilizado, de modo que haja a propagação de fluxo em todas as células do modelo. Em seguida, são realizadas etapas de determinação da(s) bacia(s) hidrográfica(s) da área representada e o produto de suas áreas de contribuição nos vetores de acumulação de fluxo, que consiste na determinação da direção de fluxo e, posteriormente, da acumulação.

Em sequência, o MDT a ser utilizado tem os pixels reclassificados em sua trajetória de fluxo superficial tendo a rede de drenagem mais próxima como referência topográfica. Ou seja, deixam de possuir o valor altimétrico estabelecido pela distância vertical em relação ao nível de base geral, o nível do mar, e passam a ter um valor de distância vertical em relação ao nível de base local, que se constitui na rede de drenagem mais próxima. Como resultado desta etapa, é produzido um MDT normalizado, onde a cada ponto de grade é ajustado um novo valor altimétrico referenciado topograficamente com a rede de drenagem.

É importante considerar que os algoritmos existentes não utilizam o mesmo princípio para normalização das cotas altimétricas com base na rede de drenagem e isso implica diretamente no resultado do arquivo com os valores altimétricos reclassificados. No primeiro algoritmo de criação do modelo desenvolvido pelos autores para o software TerraHidro conforme Renno et al. (2008), é necessário que se estabeleça um limiar sob o qual um canal de drenagem é iniciado, de modo que quanto menor é o limiar estabelecido, maior é a densidade da rede de drenagem e, consequentemente, a relevância de um canal na acumulação de fluxo (GOERL et al., 2017). Em contrapartida, o algoritmo desenvolvido por Dilts (2015) utilizado para este estudo não predita um resultado de acordo com um limiar estabelecido para iniciação de um canal, mas requer de entrada um arquivo matricial dos cursos d'água. Desse modo, o arquivo de rede de drenagem de entrada determina os seguimentos lineares de referência dos cursos d'água para a criação do modelo. 
Figura 3-Sucessão das etapas de reclassificação altimétrica do MDT.

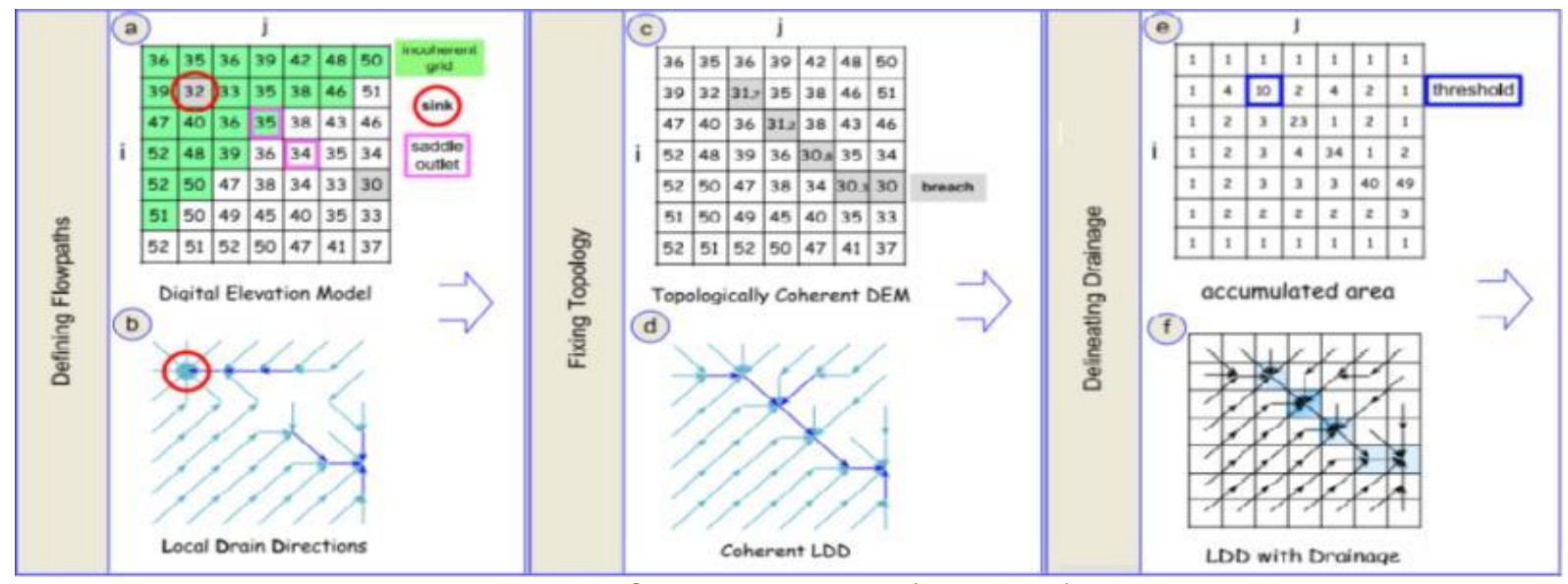

Fonte: NOBRE et al., 2011 (Adaptado).

Legenda: Procedimentos preliminares exigidos para cálculos HAND: (a) um DEM com sumidouros e topologia hidrológica parcialmente incoerente é usado como topografia de origem; (b) uma rede de vias de fluxo é definida a partir da grade de direção de drenagem local (LDD), gerada usando a abordagem D8; (c) os sumidouros são resolvidos através do rompimento da depressão, o que (d) permite a correção topológica do LDD; (e) uma grade de área acumulada é gerada calculando a área total da subida acumulada em cada célula pertencente às direções de descida, definidas respectivamente pelo LDD; e (f) é encontrado um valor limite para a área acumulada que corresponde à iniciação do canal (cabeças do fluxo), definindo assim a rede de drenagem.

A característica do algoritmo de Dilts (2015) de não definir uma rede de drenagem a partir dado altimétrico do próprio MDT utilizado viabilizou a modelagem hidrológica, pois foi possível realizar a modelagem também para os terrenos adjacentes à costa, que possuem o mar como elemento integrante da drenagem. Em áreas litorâneas, como a área de estudo em questão, a existência de corpo d'água costeiro significa que a linha de costa é referência de onde inicia a rede de drenagem de terrenos adjacentes que possuem a direção de fluxo convergente para a costa. Desse modo, sem considerar a linha de costa como referência de rede de drenagem, esses terrenos passam a não possuir uma referência espacial para, a partir dela, normalizar o valor altimétricos dos pixels que os representam. Nesse sentido, o presente estudo agrega uma nova abordagem para o estudo de inundação com o modelo HAND e estendeu a utilização do índice criado para além da normalização dos valores altimétricos de um modelo de terreno em relação à dinâmica fluvial, mas também relacionado à dinâmica marinha, uma vez que em áreas costeiras ambos os fatores atuam, seja de maneira separada ou combinadamente.

A área de estudo, na condição de espaço predominantemente urbanizado, possui uma densa rede de drenagem urbana formada por tubos, canais, valas e 
fossos. No entanto, nas sub-bacias contidas na área de estudo existem apenas sete canais que se caracterizam por serem naturais e perenes e para onde escoa a maior parte do produto das áreas de contribuição da bacia. Esses canais se caracterizam pela baixa altitude de acordo com os dados altimétricos do MDT utilizado (menos 1 metro acima do nível do mar na maior parte do curso ou em todo ele) sendo as áreas de menor altitude da bacia ao longo de suas extensões e, por isso, possuem suas vazões influenciadas pelo regime de marés, mesmo em cursos a vários quilômetros da costa. $O$ seguimento linear desses rios citados e da linha de costa foram incorporados a um arquivo matricial a ser utilizado com 0 algoritmo de Dilts (2015) para a realização da modelagem hidrológica.

\section{Teste da qualidade geométrica do MDT}

No processo de desenvolvimento da metodologia de pesquisa, foi verificado algumas inconsistências com relação aos valores altimétricos do produto de MDT da SDS e foi necessário realizar uma análise que pudesse ponderar acerca do grau de acurácia e confiabilidade do produto da SDS. Desta forma foram estabelecidos pontos de controle com um sistema RTK (Real Time Kinematic) em uma parte da área de estudo fortemente afetada pela inundação de janeiro de 2018 e onde foi possível verificar inconsistências acerca dos valores altimétricos do modelo em relação à realidade, com objetivo de servir de amostragem para inferências acerca da acurácia do MDT utilizado.

Para o procedimento de obtenção de pontos de verificação in $10 c o$, foi utilizado um receptor GNSS de modo a obter-se o posicionamento de cada ponto coletado e, posteriormente, obter a informação de acurácia por meio do Padrão de Exatidão Cartográfica para Produtos Cartográficos Digitais (PEC-PCD). 0 equipamento utilizado foi o Topcon Hiper Lite Plus, com 20 canais (GPS + GLONASS), com precisão horizontal nominal de $3 \mathrm{~mm}+1$ ppm (estático, estáticorápido) ou $10 \mathrm{~mm}+1,5 \mathrm{ppm}$ (cinemático ou $\mathrm{RTK}$ ) e precisão vertical nominal de 5 $\mathrm{mm}+1,4 \mathrm{ppm}$ (estático, estático-rápido) ou $20 \mathrm{~mm}+1,5$ ppm (cinemático ou RTK).

Foram coletados 22 pontos pelo método Real Time Kinematic (RTK). Uma área de interesse (Figura 4) foi escolhida para a amostragem, que corresponde à localidade onde se situa a Rua Beira-Rio no bairro Rio Tavares, um dos pontos mais afetados com o evento de inundação ocorrido em janeiro de 2018. O pós- 
processamento dos pontos foi realizado pelo serviço online do IBGE-PPP e permitiu validar 21 dos 22 pontos de verificação obtidos. Para o processo de verificação do PEC-PCD do MDT, foram utilizados 20 pontos, atendendo à proposta de Merchant (1982), a qual especifica que 20 pontos são adequados para a avaliação da qualidade posicional de cartas.

Figura 4- Distribuição dos pontos de verificação na área de teste.

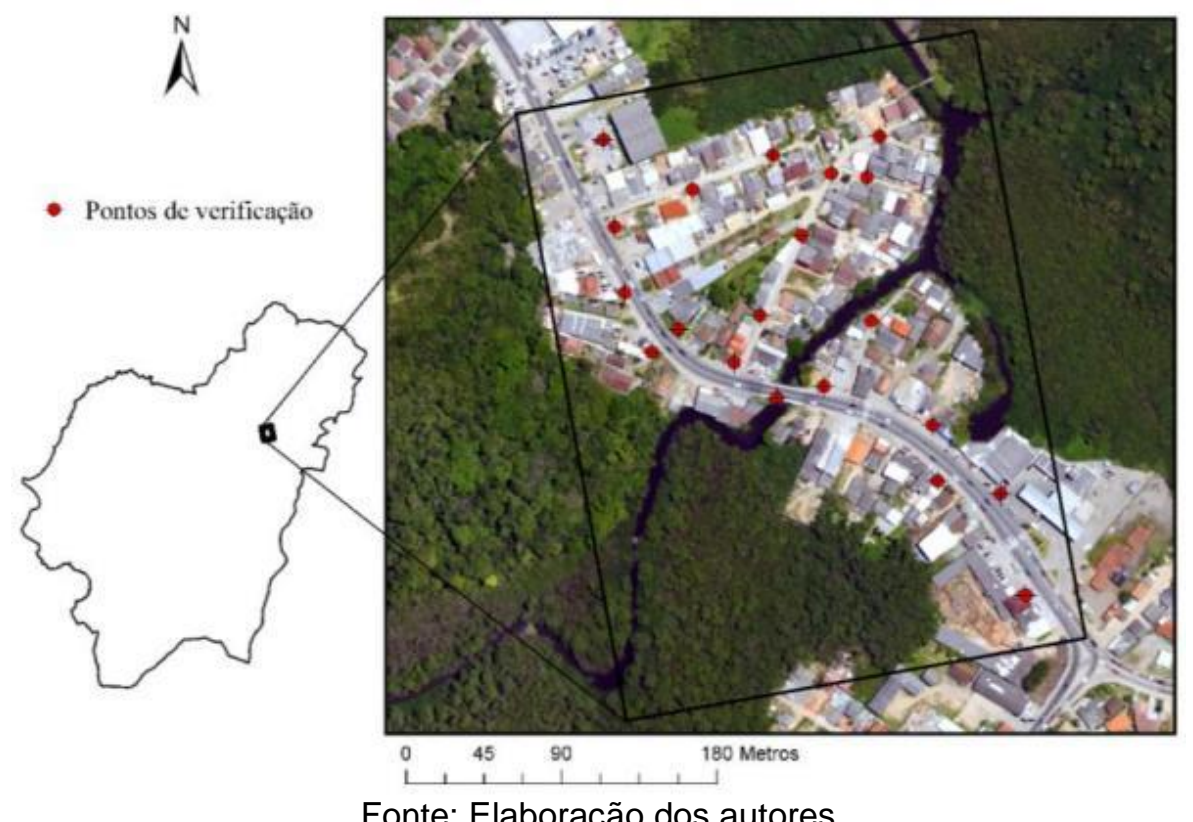

Fonte: Elaboração dos autores

Para proceder à avaliação da acurácia dos valores altimétricos do MDT utilizado, foi utilizado o programa GeoPEC (Tabela 1). O GeoPEC foi desenvolvido seguindo os procedimentos descritos nas normas técnicas, a destacar o Decreto ํㅜ 89.817 (1984) que condiciona a avaliação feita neste estudo, e na metodologia proposta por Santos et al. (2016).

Tabela 1- Resultados do PEC-PCD para o MDT da SDS.

\begin{tabular}{|l|r|}
\hline \multicolumn{2}{|c|}{ Parâmetros estatísticos } \\
\hline no pontos & 20 \\
\hline média & $0,206 \mathrm{~m}$ \\
\hline desvio padrão & $0,713 \mathrm{~m}$ \\
\hline RMS & $0,724 \mathrm{~m}$ \\
\hline
\end{tabular}

\begin{tabular}{|l|r|}
\hline \multicolumn{2}{|c|}{ Teste de normalidade (Shapiro-Wilk) } \\
\hline wecalc & 0,9224 \\
\hline p-value & 0,1102 \\
\hline Dado espacial é tendencioso? & Não \\
\hline
\end{tabular}

\begin{tabular}{|l|r|}
\hline \multicolumn{2}{|c|}{ Análise para Equist. Curva de Nível de $\mathbf{5}$ m } \\
\hline \%di $(\mathrm{H})<\mathrm{PEC}$ & $90 \%$ \\
\hline RMS < PEC & Atende \\
\hline PEC-PCD (1:10.000 - Classe A) & 1,35 \\
\hline EP (1:10.000 - Classe A) & 0,83 \\
\hline Dado espacial é acurado? & Sim \\
\hline
\end{tabular}


De acordo com o PEC-PCD obtido a partir da metodologia de Santos et al. (2016), o produto cartográfico em teste na área abrangente definida foi enquadrado como Classe A na equidistância das curvas de nível de $5 \mathrm{~m}$. De acordo com o Decreto № 89.817 (1984), esse padrão é compatível com a escala 1:10.000. Embora esse resultado seja limitado em relação à abrangência espacial, considerando que o levantamento feito pela SDS abrange todo o limite territorial de Santa Catarina, é possível aferir que o produto da SDS possui inconsistências que não permite considerá-lo acurado na equidistância máxima factível de $1 \mathrm{~m}$. Apesar disso, a área de estudo possui $57,73 \mathrm{~km}^{2}$ e é possível de ser feito mapeamento sistemático na grade 1:10.000, razão pela qual a qualidade geométrica do produto da SDS atende à proposta de análise.

\section{Validação da cota de inundação em campo}

O modelo HAND criado foi classificado em cotas altimétricas de até 1, 2 e 3 metros da drenagem mais próxima e convertida para arquivo vetorial. Foi realizada uma delimitação espacial da área construída da área de estudo, onde se concentram as residências, com a criação de um arquivo vetorial.

A fim de personalizar um mapa digital a ser utilizado em campo, foi realizada uma subtração dos polígonos de cotas altimétricas de 1, 2, 3 metros da drenagem mais próxima com os polígonos de área construída, tendo como resultado um arquivo vetorial com os polígonos das áreas construídas com altura de até 3 metros da drenagem mais próxima, estas que foram definidas como áreas de visita em campo para aplicação de um questionário com os moradores locais para constatação da ocorrência de inundação no evento de janeiro de 2018 e/ou em outras ocasiões, ou se houve inundação em julho de 2019 nas áreas com influência do regime de marés.

Foi definido que, de acordo com as características hidrogeomorfológicas da área de estudo, uma área é possivelmente inundável se possuindo até 3 metros de altura em relação à rede de drenagem mais próxima, visto que em um dos locais mais afetados, a Rua Beira-Rio (Figura 2), a altura da água medida da marca deixada em um muro até o nível do chão onde foi obtido um dos pontos de controle mostra que a altura da água não chegou a 3 metros no episódio de janeiro de 2018, estando a altura d'água da drenagem mais próxima, nesse caso o Rio Tavares, condicionada diretamente ao nível do mar naquela parte do seu curso. 
Devido ao PEC-PCD testado neste trabalho ter ponderado 1,35 $\mathrm{m}$ para acurácia, o trabalho de campo se considerou áreas com entre 3 e 5 metros de altura em relação à rede drenagem mais próxima para aplicação do questionário sobre ocasionalidade de eventos de inundação, já que se faz importante aferir, além dos locais que possivelmente inundam, se nos locais que segundo o valor altimétrico do MDT não deveriam ocorrer inundações de fato não ocorre. Desse modo, considerouse que pelo menos 2/5 dos pontos de verificação deveriam localizar-se em locais entre 3 e 5 metros de altura em relação à rede de drenagem mais próxima a fim de se obter uma boa base de comparação entre locais que inundam ou não e testar possíveis limitações na qualidade geométrica do MDT utilizado, já que cabe testar, além da capacidade do índice HAND acertar locais suscetíveis a inundação, locais que não são ou que pelo menos não tenha sido registrado.

No pré-campo, foi realizado um levantamento das áreas a serem visitadas para a validação da modelagem hidrológica. O mapa de campo constituiu-se num webmap customizado, possuindo camadas importadas em formato KML, camadas vetoriais das áreas edificadas com até 3 metros de altura em relação à rede drenagem mais próxima, as curvas de nível normalizadas pelo HAND de 1 a 5 $\mathrm{m}$ e os limites retangulares das unidades de pesquisa. $\mathrm{O}$ webmap customizado foi feito a partir do My Maps, serviço do Google Maps escolhido para utilização como ferramenta digital de geolocalização das áreas alvo de aplicação do questionário com moradores.

Figura 5- Síntese representativa dos procedimentos metodológicos realizados.

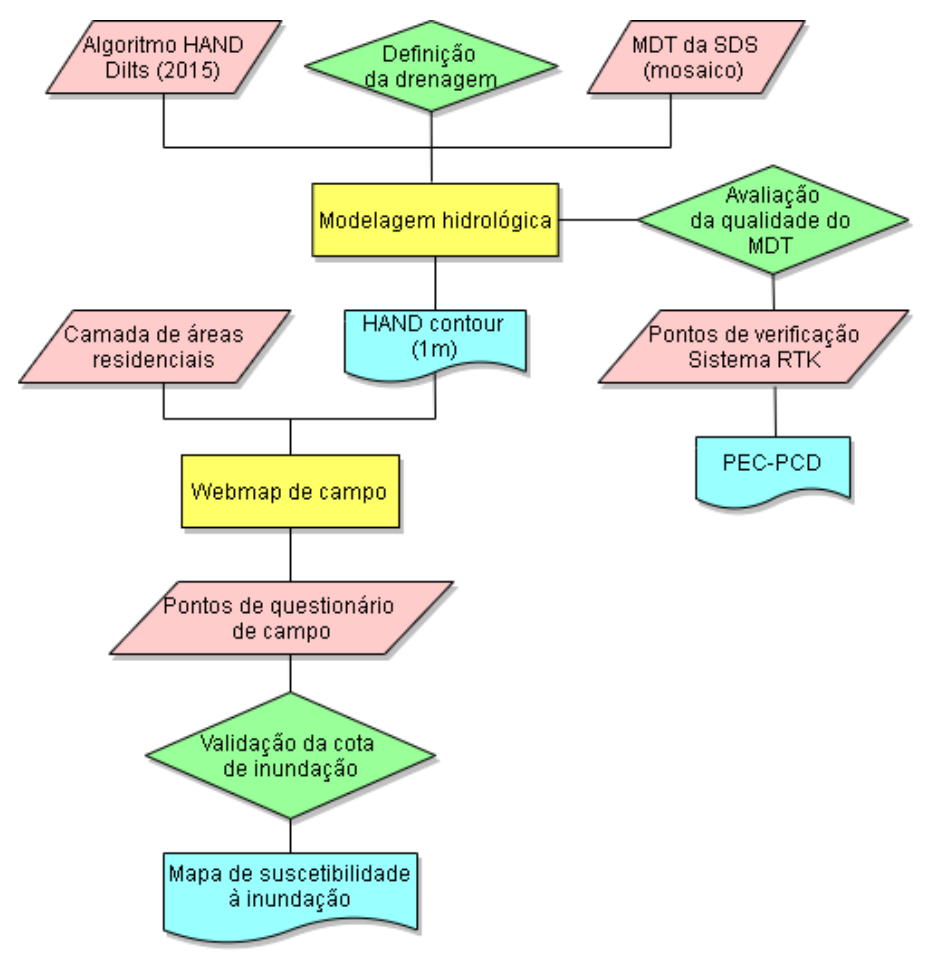


Considerando que a distribuição de ocupação na área de estudo não favorece a obtenção de pontos com expressiva distribuição espacial e que se faz necessário obter informações de locais de diferentes condições hidrogeomorfológicas, objetivou-se que a obtenção de pontos de verificação em áreas edificadas por meio de questionário fosse feita com relativa distribuição espacial. Desse modo, em cada unidade espacial, representadas por áreas retangulares de $1,47 \mathrm{~km}^{2}$, foi definido o mínimo de uma aplicação de questionário com moradores locais e o máximo de três.

A variação no número de locais de aplicação do questionário nesse intervalo em todas as unidades espaciais está relacionada, sobretudo, à existência de moradores disponíveis no dia de visita e também pela variação da densidade demográfica nas unidades espaciais, já que a tendência é de que nas unidades com mais habitantes seja mais fácil encontrar moradores em locais alvo do estudo para responder acerca daquele local. Infelizmente, em 6 das unidades espaciais não foi possível aplicar questionário, pois se situam em área de acesso restrito da Base Aérea de Florianópolis.

Nos questionários foi perguntado acerca da altura d'água em algum ponto de referência em relação à inundação de janeiro de 2018 e de fevereiro de 2019 e se houve algum prejuízo no caso dos moradores afetados. Nos pontos de entrevista e/ou de referência da altura d'água foram coletadas as coordenadas geográficas. As entrevistas foram realizadas entre 10 e 26 de agosto de 2019 e foram entrevistados de 1 a 3 moradores de cada uma das 26 unidades de pesquisa de campo. Ao todo, foram obtidas 44 respostas ao questionário, representando 44 pontos dispersos na área de estudo.

\section{Resultados}

Preliminarmente, foi estabelecida através de análise comparativa uma cota de inundação de referência que representasse a maior quantidade de pontos com registro de inundação dentro de uma margem altimétrica estabelecida para inundação e, ao mesmo tempo, a maior quantidade de pontos sem registro de inundação fora dessa margem, conforme proposto por Goerl et al. (2017). Foram testados valores em intervalos de 0,05 $\mathrm{m}$ a fim de encontrar um valor de maior correlação com os resultados do questionário de campo. 
Com um limiar de 1,65 m de cota de inundação, é possível abranger corretamente o resultado de 38 dos 44 pontos de referência obtidos em campo. Considerando a excepcionalidade dos eventos de inundação tidos como referência para este trabalho e sem descartar a hipótese de que novos eventos de maior magnitude ocorram no futuro, este estudo considerou o limiar definido como de suscetibilidade média, sendo valores medianos a este para suscetibilidade alta e baixa, desse modo: "alta" em terrenos de até $0,85 \mathrm{~m}$ de índice HAND, representando, sobretudo, locais que sofrem inundações recorrentes de menor expressão devido a eventos de chuva forte ou maré alta; "média" em terrenos entre 0,85 e 1,65 m, onde houve registros de inundação nos eventos de referência para o estudo; e "baixa" em terrenos entre 1,65 m e 2,45 m que, embora não sejam locais onde tenham sido registrados eventos de inundação, poderiam ser locais afetados se considerar a ocorrência do fenômeno em maior magnitude.

Em relação à qualidade do resultado obtido pela validação da cota altimétrica de inundação pelo índice HAND tendo por base a cota de inundação máxima prevista de acordo com os resultados obtidos pelos pontos de questionário em campo, foram analisados três índices de qualidade descritos por Brites et al. (1996), com resultado em escala de 0 a 1.

Os índices de qualidade foram calculados considerando quatro categorias possíveis para que o resultado obtido a partir dos pontos de questionário pudesse ser enquadrado. Essas categorias dizem respeito à localização do ponto em relação à cota de inundação de referência $(P<1,65 \mathrm{~m}, \mathrm{P}>1,65 \mathrm{~m})$ e à ocasionalidade do fenômeno no local. Também foi considerado duas possibilidades de avaliação: o resultado tido como teste, que diz respeito à ocasionalidade de inundação de um ponto na área de estudo a partir do HAND tendo como parâmetro a cota de referência assumida; e o resultado dos pontos de questionário em campo, tidos como referência.

Os índices descritos por Brites et al. (1996) calculados para avaliação da qualidade dos resultados obtidos foram o Exatidão Global ( $G=[a ̊ ~ M i=1 n i i] / N)$, que dispõe a quantidade de acertos em relação à quantidade total de casos; o Coeficiente Kappa (K=[PoPc]/[1-Pc]), que avalia o grau de concordância entre elementos de validação; e o Coeficiente de Correlação Tau de Kendall (T=[Po$1 / \mathrm{M}] /[1-1 / \mathrm{M}])$, que sugere o valor da exatidão obtida diretamente proporcional à possibilidade de erro, sendo: å $\mathrm{M}$ i=1nii = somatório dos pontos corretamente classificados dentro de cada classe; $\mathrm{N}=$ número total de pontos contemplados na 
matriz; Po = proporção de unidades que concordam plenamente; $\mathrm{Pc}=$ proporção de unidades que concordam por casualidade e; $M=$ número de categorias na classificação.

Figura 6- Representação das superfícies de suscetibilidade à inundação da área estudada.

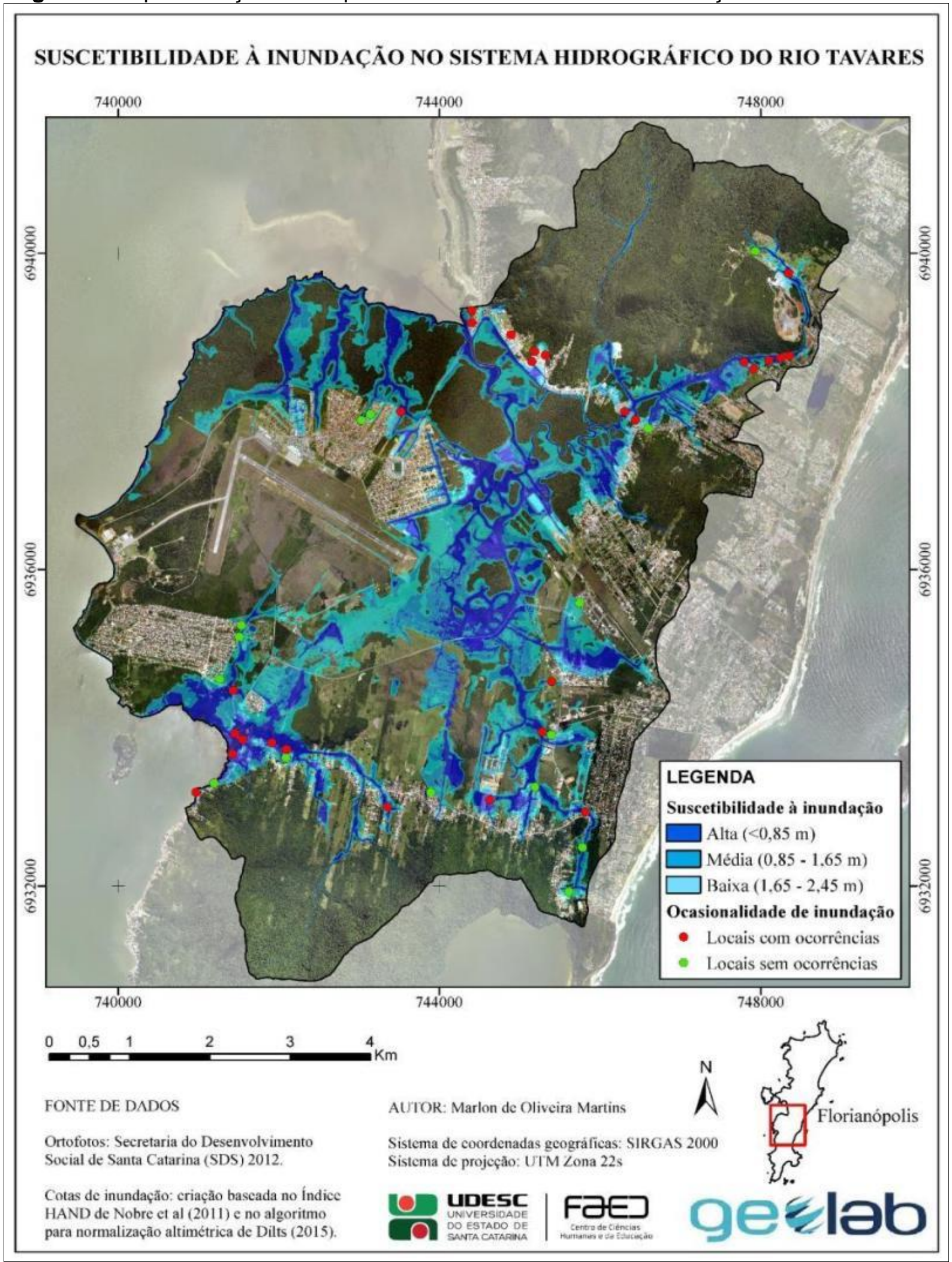

Os resultados obtidos pelos índices de qualidade calculados mostram que a metodologia construída a fim de validar uma cota altimétrica de inundação de 
referência apresentou resultados de estreita relação com os expressos a partir dos pontos de questionário em campo. É possível afirmar que a decisão de considerar apenas os canais de drenagem principais para normalizar a altimetria e criar 0 HAND contour foram adequados, haja vista que as limitações de abrangência espacial de fenômenos de inundação observada em campo mostraram que considerar toda a rede de drenagem da área de estudo para a validação do HAND criaria um resultado superestimado. Tal retorno não seria passível de validação considerando uma margem de acerto satisfatória e, sendo assim, não seria adequado para identificar áreas suscetíveis a inundação.

Baseando-se na validação da superfície potencial de inundação e nos intervalos de suscetibilidade adotados no estudo, foi estimado a representatividade dos locais suscetíveis à inundação na área estudada e, mais especificamente, do espaço de áreas residenciais. Foi possível aferir que aproximadamente $1 / 4 \mathrm{da}$ área de estudo apresenta suscetibilidade à inundação em algum grau. Em relação às áreas residenciais, a representatividade é ainda maior. Um pouco mais de $1 / 3$ do espaço de áreas residenciais apresenta suscetibilidade à inundação em algum grau. Mais da metade desses locais em áreas residenciais possuem suscetibilidade baixa $(22,1 \%)$. No entanto, a perspectiva de que aproximadamente $13,9 \%$ do espaço de áreas residenciais estão em áreas de suscetibilidade de alta e média a inundação é preocupante, pois na prática representa um número expressivo de pessoas vivendo em áreas de risco se considerado a alta densidade de ocupação residencial desses espaços urbanos.

Figura 8- Participação (\%) de áreas suscetíveis à inundação e resultados de acurácia.

Superfície inundável de acordo com o grau de suscetibilidade

$\begin{array}{lcccr}\text { Sistema Rio Tavares - SRT }\left(57,73 \mathrm{Km}^{2}\right) \text { e área residencial - AR }\left(9,19 \mathrm{~km}^{2}\right) \\ \text { Suscetibilidade } & \text { Em SRT (km²) } & \text { Em AR }\left(\mathbf{k m}^{2}\right) & \% \text { SRT } & \% \text { AR } \\ \text { Alta }(<0,85 \mathrm{~m}) & 4,36 & 0,57 & 7,6 \% & 6,2 \% \\ \text { Média }(0,85-1,65 \mathrm{~m}) & 4,79 & 0,71 & 8,2 \% & 7,7 \% \\ \text { Baixa }(1,65-2,45 \mathrm{~m}) & 5,54 & 2,03 & 9,6 \% & 22,1 \%\end{array}$

Índices de verificação de qualidade

$\begin{array}{ll}\text { Exatidão Global }(\mathrm{Po}) & 0,864 \\ \text { Kappa } & 0,820 \\ \text { TAU } & 0,818\end{array}$




\section{Considerações Finais}

O modelo HAND mostrou-se adequado na indicação de áreas suscetíveis à inundação, permitindo um melhor entendimento acerca do impacto das inundações ocorridas em janeiro de 2018 e julho de 2019 na área de estudo em questão. 0 resultado do HAND contour obtido na fase de pré-campo resultou em visitas para aplicação de questionário em locais onde havia completo desconhecimento de ocorrência de inundação ou, pelo menos, da existência de um curso d'água que pudesse provocar inundação de áreas adjacentes.

Foi possível observar em campo algumas limitações da qualidade do MDT utilizado para gerar o HAND, principalmente na região do curso inferior do Rio Tavares, onde se verificou algumas inconsistências no MDT, o que influenciou diretamente na quantidade de erros do índice validados a partir dos questionários de campo. É importante também ressaltar que a pesquisa não considerou outros eventos de inundação além dos descritos como referência principal. Uma vez que, para estas análises temporais, seria necessária uma grande série histórica de dados meteorológicos da área estudada, dados estes não disponíveis, visto que não existe uma estação meteorológica com série histórica disponível próxima à área estudada.

Um fator também limitante à modelagem em eventos passados são as sucessivas alterações no uso e ocupação da terra, que exigem outras técnicas de mapeamento e modelagem para permitir uma análise histórica da ocorrência de eventos de inundação. Diversas áreas foram aterradas por construções particulares e obras públicas ao longo do tempo da área de estudo. Nos questionários de campo, moradores de diferentes partes da área estudada chegaram a afirmar não haver mais inundações em tais localidades após o aterramento de determinadas áreas. Isto decorre provavelmente do fato de que ruas tiveram seus níveis elevados ou cursos d'água tiveram seus leitos definidos, alargados e/ou aprofundados, o que veio a encontro à premissa de inviabilidade de análises temporais com dados de terreno atuais.

Outra limitação deste estudo se apoia na impossibilidade de locais para validação de questionário com a população, já que não seria possível interrogar amplamente a população sobre eventos que ocorreram há muito tempo atrás e obter informações seguras. Outrossim, a distribuição populacional na área se modificou muito ao longo das últimas décadas. E, por fim, a complexidade da atuação dos processos da dinâmica fluvial e marinha, observando-se que parte dos terrenos do recorte espacial estudado sofre influência é também um fator limitante à análise 
temporal e possíveis simulações, visto que, como mencionado anteriormente, a atuação desses processos de diferentes naturezas pode se somar ou se anular.

\section{REFERÊNCIAS}

BASTOS, M. (2004). Atlas do município de Florianópolis. Florianópolis: Instituto de Planejamento Urbano de Florianópolis (IPUF). 166 p.

BRASIL. Decreto n 89.817 de 20 de junho de 1984 - Normas Técnicas da Cartografia Nacional. Diário Oficial da União, Brasília, Brasil, 1984. Disponível em:

http://www.planalto.gov.br/ccivil_03/decreto/1980-1989/D89817.htm. Acesso em: 29 abr. 2020.

BRASIL. MINISTÉRIO DAS CIDADES / INSTITUTO DE PESQUISAS TECNOLÓGICAS IPT. Mapeamento de Riscos em Encostas e Margem de Rios / Celso Santos Carvalho, Eduardo Soares de Macedo e Agostinho Tadashi Ogura, (Org.). Brasília: Ministério das Cidades; Instituto de Pesquisas Tecnológicas - IPT, 2007.

BRITES, R. S.; SOARES, V. P.; RIBEIRO, C. A. A. S. Verificação da exatidão em classificação de uma imagem orbital mediante a utilização de três índices. Revista Árvore, v. 20, n. 3 , p. $415-424,1996$

DILTS, T.E. (2015) Topography Tools for ArcGIS 10.1. University of Nevada Reno. Disponível em:

<http://www.arcgis.com/home/item.html?id=b13b3b40fa3c43d4a23a1a09c5fe96b9>. Acesso em: 15 Mar. 2019.

EMPRESA DE PESQUISA AGROPECUÁRIA E EXTENSÃO RURAL DE SANTA

CATARINA (Santa Catarina). EPAGRI/CIRAM: Costa de Santa Catarina registra super maré no início de julho. Florianópolis, 8 jul. 2019. Disponível em:

https://www.epagri.sc.gov.br/index.php/2019/07/08/costa-de-santa-catarina-registra-supermare-no-inicio-de-julho/. Acesso em: 07 mai. 2020.

GOERL, Roberto Fabris; MICHEL, Gean Paulo; KOBIYAMA, Masato. Mapeamento de áreas susceptíveis a Inundação com o modelo HAND e análise do seu desempenho em diferentes resoluções espaciais. Revista Brasileira de Cartografia, n. 69/1, p. 61-69, Edição Especial Geotecnologias e Desastres Naturais, 2017.

HERRMAN, M. L. P.; ROSA, R. de O. Mapeamento temático do município de Florianópolis - Geomorfologia. Florianópolis: IPUF/IBGE. 1991.

INSTITUTO NACIONAL DE METEOROLOGIA (Brasil). BDMEP: Série histórica - dados mensais - precipitação total $(\mathrm{mm})$ - Florianópolis. Brasília, 2010. Disponível em:

http://www.inmet.gov.br/projetos/rede/pesquisa/inicio.php. Acesso em: 7 mai. 2020.

MERCHANT, D. C. Spatial accuracy standards for large scale line maps. In: American Congress on Surveying and Mapping, v.1, 1982. Technical Papers of the American Congress on Surveying and Mapping, 1982.

MILANESI, J.; QUADROS, E. L. L.; LAHNM, R. A. Utilização do modelo HAND no reconhecimento dos terrenos sujeitos a inundação - Porto Alegre/RS. Revista Brasileira de Cartografia, n. 69/4, p. 675-686, Abr/2017. 
MOMO, Marcos Rodrigo; PINHEIRO, Adilson; SEVERO, Dirceu Luís; CUARTAS, Luz Adriana; NOBRE, Antonio Donato. Desempenho do modelo HAND no mapeamento de áreas suscetíveis à inundação usando dados de alta resolução espacial. Revista Brasileira de Recursos Hídricos v.21, n. 200-208, Porto Alegre Jan./Mar. 2016.

NEVES, J.; ORNON, A.; VOIRON-CANÍCIO, C.; FILHO, N. O. H. Mapeamento do uso e cobertura da terra da Ilha de Santa Catarina, Brasil, com base em imagem de alta resolução espacial. Geosul, Florianópolis, v. 32, n. 65, p. 213-138, set/dez. 2017.

NOBRE, A. D.; CUARTAS, L. A.; MOMO, M. R.; PINHEIRO, A.; SEVERO, D. L.; NOBRE, C. A. HAND contour: calibration-independent new predictor of inundation extent. Hydrological Processes. 2015.

NOBRE, A. D.; CUARTAS, L. A.; HODNETT, M. G.; RENNÓ, C. D.; RODRIGUES, G.; SILVEIRA, A.; WATERLOO, M.; SALESKA, S. Height Above the Nearest Drainage - a hydrologically relevant new terrain model. Journal of Hydrology, v. 404, n. 1, p. 13-29, 2011.

RAHMATI, O.; KORNEJADY, A.; SAMADI, M.; NOBRE, A. D.; MELESSE, A. M. Development of an automated GIS tool for reproducing the HAND terrain model. Environmental Modelling \& Software, v. 102, p. 1-12, Abr. 2018.

RENNÓ, C. D.; NOBRE, A. D.; CUARTAS, L. A.; SOARES, J. V.; HODNETTC, M. G.; TOMASELLA, J.; WATERLOOC, M. J. HAND, a new terrain descriptor using SRTM-DEM: Mapping terra-firme rainforest environments in Amazonia. Eselvier - Remote Sensing of Environment, v.112, n. 9, p. 3469-3481, 2008.

SANTOS, V. F. Dinâmica de inundação em áreas úmidas costeiras: zona urbana de Macapá e Santana, costa amazônica, Amapá. PRACS: Revista Eletrônica de Humanidades do Curso de Ciências Sociais da UNIFAP. Macapá, v. 9, n. 3, p. 121-144, dez. 2016.

SANTOS, A. P.; RODRIGUES, D. D.; SANTOS, N. T.; GRIPP JUNIOR, J. Avaliação da acurácia posicional em dados espaciais utilizando técnicas de estatística espacial: proposta de método e exemplo utilizando a norma brasileira. Boletim de Ciências Geodésicas, v. 22, n. 4, p. 630-650, 2016.

SPECKHANN, Gustavo Andrei. Uma proposta de mapeamento de risco de inundação na bacia do Rio Itajaí utilizando descritores de terreno. Dissertação (Mestrado em Engenharia Ambiental). Universidade Federal de Santa Catarina, Florianópolis - SC, 2018.

TOMINAGA, L.K.; SANTORO, J.; AMARAL, R. Desastres naturais: conhecer para prevenir. Lídia K. Tominaga, Jair Santoro, Rosangela do Amaral (Orgs.). São Paulo: Instituto Geológico, 2009, 196 p.

\section{NOTAS DE AUTOR}

\section{CONTRIBUIÇÃO DE AUTORIA}

Marlon de Oliveira Martins - Concepção. Coleta de dados, Análise de dados, Elaboração do manuscrito, revisão e aprovação da versão final do trabalho.

Rodrigo Pinheiro Ribas - Concepção, elaboração e revisão do manuscrito. Participação ativa da discussão dos resultados. 


\section{CONSENTIMENTO DE USO DE IMAGEM}

Foi obtido consentimento escrito da gerência de conteúdo digital da NSC Comunicação para divulgação de imagem da cheia no bairro do Rio Tavares (Florianópolis - SC) em 11 de janeiro de 2018.

\section{APROVAÇÃO DE COMITÊ DE ÉTICA EM PESQUISA}

Não se aplica.

\section{CONFLITO DE INTERESSES}

Não se aplica.

\section{LICENÇA DE USO}

Este artigo está licenciado sob a Licença Creative Commons CC-BY. Com essa licença você pode compartilhar, adaptar, criar para qualquer fim, desde que atribua a autoria da obra.

\section{HISTÓRICO}

Recebido em: 22-05-2020

Aprovado em: 01-02-2021 